\title{
Gene expression of estrogen and oxytocin receptors in the uterus of pregnant and parturient bitches
}

\author{
G.A.L. Veiga ${ }^{1}$, M.P. Milazzotto ${ }^{2}$, M. Nichi ${ }^{1}$, C.F. Lúcio ${ }^{1}$, L.C.G. Silva ${ }^{1}$ \\ D.S.R. Angrimani ${ }^{1}$ and C.I. Vannucchi ${ }^{1}$ \\ ${ }^{1}$ Departamento de Reprodução Animal, Faculdade de Medicina Veterinária e Zootecnia, \\ Universidade de São Paulo, São Paulo, SP, Brasil \\ ${ }^{2}$ Centro de Ciências Naturais e Humanas, Universidade Federal do ABC, Santo André, SP, Brasil
}

\begin{abstract}
In the canine species, the precise mechanisms of pregnancy maintenance and the initiation of parturition are not completely understood. The expression of genes encoding the receptors for estrogen (ER $\alpha$ mRNA) and oxytocin (OTR mRNA) was studied in the endometrium and myometrium during pregnancy and parturition in dogs. Real-time PCR was performed to quantify the levels of $E R \alpha \mathrm{mRNA}$ and OTR mRNA in the uterus of bitches during early (up to 20 days of gestation), mid (20 to 40 days) and late pregnancy (41 to 60 days), and parturition (first stage of labor). All tissues expressed ER $\alpha$ and OTR mRNA, and are thus possibly able to respond to eventual estrogen and oxytocin hormonal stimuli. No statistically significant differences in the expression of $E R \propto$ mRNA were verified in the endometrium and myometrium throughout pregnancy and parturition, but expression of OTR mRNA increased at both parturition and late pregnancy. We concluded that the increase of endometrial and myometrial OTR $m R N A$ expression in dogs is not an event dependent on estrogenic stimulation. Moreover, the contractility response of the canine uterus to oxytocin begins during pregnancy and maintains myometrial activity. The expression of OTR mRNA in canine uterine tissues varied over time, which supports an interpretation that the sensitivity and response to hormone therapy varies during the course of pregnancy and labor. Further studies are needed to elucidate the factors underlying the synthesis of uterine oxytocin receptors and the possible role of $E R \beta$ rather than $E R \alpha$ in the uterine tissues during pregnancy and parturition in dogs.
\end{abstract}

Key words: Canine; Estrogen; Oxytocin; Receptors; Pregnancy; Parturition

\section{Introduction}

The control of gestation and parturition depends on hormones from various organs, such as the ovaries, placenta and pituitary, which in turn act on many target organs (e.g., the uterus, corpus luteum and mammary glands). During the final period of gestation, it is known that hormonal interactions among progesterone, estrogen, prostaglandins and oxytocin occur, mainly to achieve an appropriate uterine tonus as parturition approaches. In the canine species, the exact mechanisms of pregnancy maintenance and the initiation of parturition are not completely known.

Progesterone is the essential hormone for pregnancy maintenance, as it suppresses uterine contractions by preventing the uterotonic action of estrogen (1). In the pregnant dog, the peripartum peak values of prostaglandins and the abrupt prepartum decrease in progesterone are the crucial events for initiation of parturition (2). In dogs, and several other species, placental and/or uterine release of prostaglandin is thought to be initiated by increased fetal cortisol secretion $(3,4)$. Moreover, estrogen is the hormone that stimulates parturition by increasing the expression of the genes associated with myometrial excitability and contraction, and increases uterine sensitivity to oxytocin during the course of pregnancy (5). In fact, at later stages of pregnancy, the expression of estrogen receptor alpha $(E R \alpha)$ mRNA in the uterus of bitches increases, compared with earlier phases (6). Murata et al. (7) showed that the control of the expression of oxytocin receptor (OTR) mRNA in the uterus of rats is mediated by $E R \alpha$, this latest event stimulated by a decline in progesterone concentration. However, the classic placental steroidogenic activity that triggers the prepartum estrogen rise has not been confirmed in dogs (1,7). Additionally, Hoffman et al. (8) showed a rapid decrease in estrogen levels prior to parturition in pregnant dogs, suggesting a nondirect action of estradiol on the

Correspondence: C.I. Vannucchi: <cacavann@usp.br>.

Received March 17, 2014. Accepted October 10, 2014. First published online February 13, 2015. 
preparation of the genital tract for whelping. Therefore, we hypothesized that, in spite of low plasma estrogen concentrations, uterine sensitivity to estrogen is increased by means of an increase in estrogen receptors that is responsible for the uterotonic action towards parturition in pregnant dogs.

The endocrine and paracrine action of oxytocin is important for activation of the uterine musculature, ripening of the cervix, and opening of the birth canal (9). However, the exact action of oxytocin during parturition is not yet known, as circulating levels of oxytocin only start to rise in pregnant bitches during the second stage of labor (10). In ewes, Garcia-Villar et al. (11) reported regular electrical uterine activity during the third phase of pregnancy that was under the control of estrogens produced by the fetoplacental unit. Again, the canine placenta lacks steroidogenesis, leaving the eventual uterine motility an unexplained event in dogs. However, there is evidence in sheep that spontaneous contractures during pregnancy are probably due to local mechanisms within the myometrium (12). In bitches, the expression of uterine OTR mRNA is higher in the final stages of pregnancy, compared with other phases (6). However, the study of Derussi et al. (6) reported the overall expression of oxytocin receptor in the canine uterus, and did not provide results specific to the uterine layers (endometrium and myometrium). Hence, our hypothesis was that in the canine species, the increase in myometrial OTRs plays a major role in uterine sensitivity during gestation, with peak sensitivity occurring towards parturition.

During the last decade, several studies have been performed with the paramount goal of improving the reproductive efficiency of animals. However, in the case of dogs, few studies have been designed to broaden understanding of the endocrinological modifications, especially during the periods of pregnancy and whelping. Moreover, study of the reproductive events in the canine species can serve as a reference for an understanding of the reproductive physiology of carnivores more generally, as the dog is considered an important animal model. In the present study, we aimed to characterize the expression of ER $\alpha$ and OTR in the canine endometrium and myometrium in pregnant and parturient bitches. These results will help to highlight the specific hormonal sensitivity of the uterine tissues and, ultimately, contribute to development of hormone therapies during pregnancy and birth.

\section{Materials and Methods}

\section{Animals and experimental groups}

The use of animals in the current study was approved by the Bioethics Committee of the Faculdade de Medicina Veterinária e Zootecnia, Universidade de São Paulo. Bitches were privately owned and had been subjected to mismating and unwanted pregnancy. All owners were aware of the pregnancy interruption and agreed with the gonadectomy.
Pregnant bitches of different breeds, ages and parity were assigned to 4 groups by gestational age as established by ultrasound, reproductive history, and measure of the fetal crown-rump length (13): up to 20 days of gestation (Early pregnancy group, $n=11$ ); 20 to 40 days of gestation (Mid pregnancy group, $n=12$ ); 41 to 60 days of gestation (Late pregnancy group, $n=12$ ); and first stage of labor (Parturition group, $n=11$ ). Clinical signs of the early phase of labor were vaginal elimination of the mucus plug, drop in body temperature, and behavioral alterations such as isolation, restlessness, and lack of appetite. The pregnant females were subjected to ovariohysterectomy, and animals in the Parturition group underwent cesarean section followed by ovariohysterectomy.

After surgery, fragments of the endometrium and myometrium were harvested. After placental detachment, myometrium samples were dissected from the endometrium (always at the same uterine site), according to the macroscopic appearance of the uterine tissues. Fragments were washed with $0.9 \% \mathrm{NaCl}$, and stored at $-196^{\circ} \mathrm{C}$ until further processing.

\section{RNA isolation and cDNA synthesis}

The Illustra RNAspin Mini RNA Isolation kit (GE Healthcare ${ }^{\mathbb{R}}$, Germany) was used to extract total RNA from the samples of endometrium and myometrium, following the manufacturer's instructions. Total RNA was quantified after dilution in RNase-free water at a ratio of 1:100 in a photometer (model Vi 1.35, Eppendorf ${ }^{\mathbb{R}}$, Germany). Subsequently, $1 \mu \mathrm{g}$ total RNA was used to synthesize the first strand of cDNA by reverse transcription using the Super Script ${ }^{\mathbb{R}}$ II reverse transcriptase (Invitrogen ${ }^{\mathbb{R}}$, USA) system in the presence of oligo(dT). Initially, total RNA was mixed with $1 \mu \mathrm{L}$ oligo(dT), and diethylpyrocarbonate (DEPC)-treated water was added to a total volume of $12 \mu \mathrm{L}$; the reaction mixture remained at $70^{\circ} \mathrm{C}$ for $10 \mathrm{~min}$ in a PTC- $100^{\mathrm{R}}$ thermal cycler (Bio-Rad, USA). The solution was cooled to $-20^{\circ} \mathrm{C}$ for $1 \mathrm{~min}$. Afterwards, $2 \mu \mathrm{L}$ of first strand buffer, $2 \mu \mathrm{L}$ of $\mathrm{MgCl}_{2}$ $25 \mathrm{mM}, 1 \mu \mathrm{L}$ of deoxyribonucleotide triphosphate (dNTP), and $2 \mu \mathrm{L}$ of $0.1 \mathrm{M}$ dithiothreitol (DTT) were added followed by heating to $42^{\circ} \mathrm{C}$ for 5 min. Finally, $1 \mu \mathrm{L}$ of SuperScript ${ }^{\mathrm{R}}$ II enzyme (Invitrogen ${ }^{\mathbb{R}}$ ) was added and the reaction was kept at $42^{\circ} \mathrm{C}$ for $50 \mathrm{~min}$ and $70^{\circ} \mathrm{C}$ for $15 \mathrm{~min}$. The synthesized cDNA was stored at $-20^{\circ} \mathrm{C}$.

\section{Real-time PCR amplification}

To quantify their levels of genetic expression, comparative analysis of the ER $\alpha$ and OTR target genes and 18S rRNA and ribosomal protein (RP)S5 endogenous controls was performed. The cDNAs were subjected to amplification of $18 S$ and RPS5 constitutive genes as well as ER $\alpha$ and OTR using primers designed from sequences previously deposited in GenBank (www.ncbi.nml.nih.gov). In order to avoid false positive results, primers were constructed with the intron region of the amplicon.

The primer sequences were as follows: $18 S$, 5'-TGGTT 
GATCCTGCCAGTAGCA-3' and 5'-ATGAGCCATTCGCA GTTTCACT-3'; RPS5, 5'-TCACTGGTGARACCCCCT-3' and 5'-CCTGATTCACACGGCGTAG-3'; ER $\alpha, 5^{\prime}$-GGTCTT GGTGTTGGGTGTG-3' and 5'-GGACATATTCCTCACGC TCC-3'; OTR, 5'-GAACTTGTACAGCGCTTCCTC-3' and 5'-GACAAAGGTGGATGAGTTGCTC-3'.

Real-time PCR was performed in an Eppendorf ${ }^{\mathbb{R}}$ Mastercycler Realplex using the Platinum ${ }^{\mathbb{R}}$ SYBR Green PCR Master Mix kit (Invitrogen ${ }^{\mathbb{R}}$ ). All reactions were performed in a total volume of $25 \mu \mathrm{L}$ and heated to $50^{\circ} \mathrm{C}$ for $2 \mathrm{~min}$ and then $95^{\circ} \mathrm{C}$ for $10 \mathrm{~min}$, followed by 45 cycles comprising denaturation at $95^{\circ} \mathrm{C}$ for $15 \mathrm{~s}$ and then annealing for $60 \mathrm{~s}$ at the following temperatures: $61^{\circ} \mathrm{C}$ for RPS5, $60^{\circ} \mathrm{C}$ for $18 \mathrm{~S}$, and $59^{\circ} \mathrm{C}$ for ER $\alpha$ and OTR. All reactions were performed in duplicate.

To calculate the relative expression levels of the target genes, Pfaffl's formula (14) was applied. The efficiency of the amplification reactions for the different genes was established by amplifying serial dilutions of each sample. The relative efficiency (target gene/endogenous gene) was calculated from the slopes of product formation curves, where efficiency $=10^{-1 / \text { slope }}$. The relative amplification efficiencies for the analyzed genes were 1.98 (18S), 2.05 (RPS5), 2.08 (ER $\alpha$ ), and 1.94 (OTR).

\section{Statistical analysis}

All data were evaluated using the SAS System for Windows (SAS Institute Inc., USA). The effect of gestational period (Early pregnancy, Mid pregnancy, Late pregnancy, and Parturition) was determined using parametric (one-way ANOVA using PROC GLM and LSD as a post hoc test) and nonparametric (Wilcoxon) tests, according to the residual normality (Gaussian distribution) and variance homogeneity of each variable. A probability value of $\mathrm{P}<0.05$ was considered to be statistically significant. Results are reported as untransformed means \pm SE. To verify the stability of the endogenous controls (RPS5 and 18S) in each tissue (endometrium and myometrium), the variance of each was compared using the Brown-Forsythe test.

\section{Results}

No statistical difference was observed for the variance homogeneity of the endogenous controls (18S and RPS5) in the myometrium. However, the $18 S$ gene presented a higher variance in the endometrium than the RPS5 gene. Hence, all data are reported in relation to the RPS5 reference gene.

No statistical difference was observed throughout pregnancy for the expression of $E R \alpha \mathrm{mRNA}$ in the endometrium (Figure 1). The highest expression of OTR mRNA occurred during parturition (Figure 1). Moreover, no difference in OTR mRNA expression in the endometrium was observed during gestation (Figure 1).

From early pregnancy onward, no statistical difference was observed for $E R \alpha \mathrm{mRNA}$ expression in the myometrium

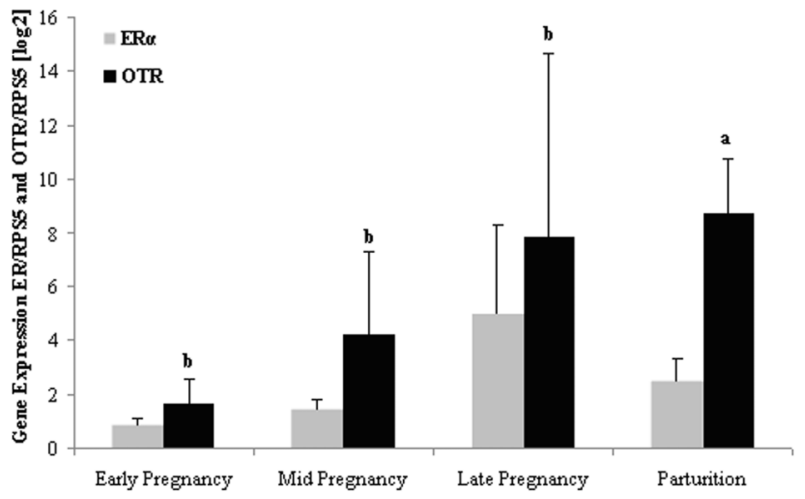

Figure 1. Relative expression of estrogen receptor $(E R \alpha)$ and oxytocin receptor $(O T R)$ in the endometrium during Early $(n=11)$, Mid $(n=12)$ and Late pregnancy $(n=12)$ and Parturition $(n=11)$. ${ }^{a, b}$ Significantly different among groups $(P<0.05$, LSD test).

(Figure 2). The expression of OTR mRNA increased in the myometrium $(P<0.05)$ from gestational day 41 (Late pregnancy group), but was not different from that in the Parturition group (Figure 2).

\section{Discussion}

In this study, we examined the temporal expression of ER $\alpha \mathrm{mRNA}$ and OTR mRNA simultaneously in the endometrium and myometrium during gestation and parturition in dogs. All tissues expressed mRNA for ER $\alpha$ and OTR; consequently they may be able to respond to eventual hormonal stimulation by estrogen and oxytocin.

The expression of ER $\alpha$ mRA in the endometrium remained similar across all the gestational phases and at the beginning of labor. Progesterone downregulates nuclear estrogen receptor in the ovine endometrium and consequently also suppresses the formation of oxytocin receptors (15). The control of OTR mRNA in the uterus is mediated by $E R \alpha$, which in turn is induced by a decline in progesterone

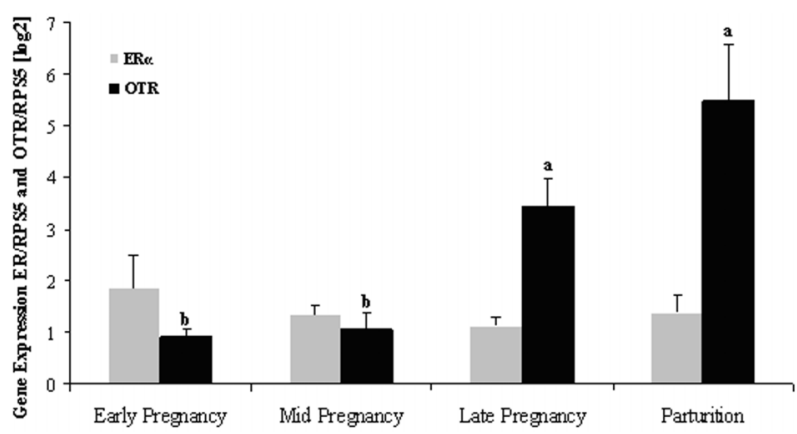

Figure 2. Relative expression of estrogen receptor $(E R \alpha)$ and oxytocin receptor (OTR) in the myometrium during Early $(n=11)$, Mid $(n=12)$ and Late pregnancy $(n=12)$ and Parturition $(n=11)$. ${ }^{a, b}$ Significantly different among groups $(P<0.05$, LSD test). 
concentrations. However, in the present work, both endometrial ER $\alpha$ mRNA and OTR mRNA remained unchanged until late pregnancy, suggesting a down-regulation mechanism of the estrogen-oxytocin system that is of unknown origin. Nevertheless, Derussi et al. (6) showed increased expression of ER $\alpha$ mRNA and OTR mRNA in the uterus of bitches in advanced stages of pregnancy. Such a difference might be attributed to distinct methodological procedures, as those authors investigated all uterine tissue. Additionally, we cannot rule out the influence of having a small number of bitches in each group in the present study. Thus, more studies are necessary with larger experimental groups to accurately detect any statistically significant differences in the expression of OTR mRNA and ER $\alpha$ mRNA in the myometrium and endometrium of pregnant bitches.

During parturition, we observed an increased expression of endometrial OTR mRNA, which was not accompanied by a rise in ER $\alpha$ mRNA expression. Hence, we can speculate that the increase in endometrial OTR mRNA expression in dogs is a progesterone decrease-dependent event rather than a result of estrogen stimulation. In pregnant bitches, there is a gradual increase in prostaglandin concentrations over time, with peak concentrations occurring immediately prepartum $(2,16)$, similar to the OTR pattern observed in the myometrium in this study. Moreover, a constant expression of OTR was verified in the uterus of bitches from preimplantation until midgestation, with a significant increase before parturition (17). Hence, we can infer that the increase in endometrial OTRs is linked to the peak levels of prostaglandins during the onset of parturition in dogs, in order to start the active labor and promote powerful contractions. In fact, Gram et al. (17) reported that OTR is involved in the prepartum release of prostaglandins in bitches, as OTR is upregulated in antiprogestagenic-treated dogs, being colocalized with the progesterone receptor. However, it is important to point out that estrogen has ubiquitous activity during pregnancy, with its receptor subtypes (ER $\alpha$ and $E R \beta)$ present in various target tissues (18). In pregnant rats, the induction of OTR mRNA in the uterus appears to be mediated by $E R \beta$ and not by $E R \alpha(7)$. The existence of two estrogen receptor subtypes explains the differential action of estrogen in its target tissues in an autocrine and/or paracrine manner (19). Thus, we suggest a possible involvement of ER $\beta$ mRNA in the control of OTR mRNA expression in pregnant dogs at the end of pregnancy. Hence, further studies are required to elucidate the role of $E R \beta$, as well as the progesterone receptor, in the endometrium of pregnant dogs.

By the end of pregnancy, the crucial endocrine event in sheep and rats is determined by declining serum progesterone concentrations and increasing estrogen concentrations, resulting in the synthesis of the uterine OTR during parturition $(20,21)$. Our findings demonstrated a progressive increase in myometrial sensitivity (OTR) to stimulation by oxytocin. In pregnant women, labor is preceded by increased expression of $E R \alpha$ in the myometrium, concomitant with a reduction in progesterone concentrations (22). Although we observed an increased expression of OTR mRNA in the myometrium of dogs towards late pregnancy and parturition, the expression of ER $\alpha$ mRNA remained unchanged. As in the endometrium, the induction of OTR mRNA synthesis associated with ER $\alpha$ could not be verified in the myometrium in this study. Therefore, we do not accept the hypothesis of a high local endometrial and myometrial sensitivity to estrogen. The factor underlying the synthesis of uterine OTRs remains to be elucidated in dogs. However, as previously mentioned, we can assume that the modulation of OTRs in pregnant dogs occurred mainly due to the action of $E R \beta$ and to a lesser degree to that of $E R \alpha$.

We observed an increase in OTR in the myometrium, earlier in late pregnancy (41-60 days). That is, the preparation for uterine contractions starts before the active labor. As in other species, myometrial activity is observed during pregnancy $(11,23)$. Although we observed an increase in myometrial OTR mRNA early in late pregnancy, plasma oxytocin concentration is low in pregnant dogs at that time (24). The asynchrony between oxytocin level and the expression of myometrial OTR prevents precocious expulsive contractions during pregnancy. On the other hand, during the second stage of parturition, the oxytocin concentration is elevated (24), coincidently with our findings of elevated OTR expression in the myometrium. Hence, we assume that the contractility response of the canine uterus to oxytocin begins during pregnancy, maintaining myometrial activity. However, expulsive contractions commence only with the rise in oxytocin levels at the onset of the second stage of parturition.

We observed that the expression levels of OTR mRNA in canine uterine tissues vary over time, which supports the idea that the sensitivity and response to hormone therapy can vary during the course of pregnancy and labor. Thus, treatment of the periparturient bitch with hormones has to be adjusted in a time-dependent manner. The expression of OTR mRNA appears to be mediated by progesterone receptor $(P R)$ or $E R \beta$ rather than by $E R \alpha$ in the investigated tissues. The interesting results obtained here highlight the need for further studies on protein expression by Western blotting or immunohistochemistry in order to clarify our understanding of the endocrine mechanisms related to pregnancy and parturition in the canine species.

To our knowledge, this is the first research communication to simultaneously assess hormonal receptors in the myometrium and endometrium in the distinct phases of gestation in dogs. Hence, our results can be used as a reference model for the study of pregnancy and parturition in other carnivores, including wild species. 


\section{References}

1. Onclin K, Murphy B, Verstegen JP. Comparisons of estradiol, $\mathrm{LH}$ and $\mathrm{FSH}$ patterns in pregnant and nonpregnant beagle bitches. Theriogenology 2002; 57: 1957-1972, doi: 10.1016/ S0093-691X(02)00644-1.

2. Concannon PW, Isaman L, Frank DA, Michel FJ, Currie WB. Elevated concentrations of 13,14-dihydro-15-keto-prostaglandin F-2 alpha in maternal plasma during prepartum luteolysis and parturition in dogs (Canis familiaris). J Reprod Fertil 1988; 84: 71-77, doi: 10.1530/jrf.0.0840071.

3. Concannon PW, Butler WR, Hansel W, Knight PJ, Hamilton JM. Parturition and lactation in the bitch: serum progesterone, cortisol and prolactin. Biol Reprod 1978; 19: 1113-1118, doi: 10.1095/biolreprod19.5.1113.

4. Veronesi MC, Battocchio M, Marinelli L, Faustini M, Kindahl $\mathrm{H}$, Cairoli F. Correlations among body temperature, plasma progesterone, cortisol and prostaglandin F2alpha of the periparturient bitch. J Vet Med A Physiol Pathol Clin Med 2002; 49: 264-268, doi: 10.1046/j.1439-0442.2002.00410.x.

5. Fuchs AR, Ivell R, Ganz N, Fields MJ, Gimenez T. Secretion of oxytocin in pregnant and parturient cows: corpus luteum may contribute to plasma oxytocin at term. Biol Reprod 2001; 65: 1135-1141, doi: 10.1095/biolreprod65.4.1135.

6. Derussi AA, de Souza RW, Volpato R, Guaitolini $C R$, Ackermann CL, Taffarel MO, et al. Progesterone (PR), oestrogen (ER-alpha and ER-beta) and oxytocin (OTR) gene expression in the oviduct and uterus of pregnant and nonpregnant bitches. Reprod Domest Anim 2012; 47 (Suppl 6): 197-199, doi: 10.1111/rda.12015.

7. Murata T, Narita K, Honda K, Matsukawa S, Higuchi T. Differential regulation of estrogen receptor alpha and beta mRNAs in the rat uterus during pregnancy and labor: possible involvement of estrogen receptors in oxytocin receptor regulation. Endocr J 2003; 50: 579-587, doi: 10.1507/endocrj. 50.579.

8. Hoffmann B, Riesenbeck A, Schams D, Steinetz BG. Aspects on hormonal control of normal and induced parturition in the dog. Reprod Domest Anim 1999; 34: 219-226, doi: 10.1111/ j.1439-0531.1999.tb01244.x.

9. Mitchell BF, Fang X, Wong S. Metabolism of oxytocin in rat uterus and placenta in late gestation. Biol Reprod 1997; 57: 807-812, doi: 10.1095/biolreprod57.4.807.

10. Olsson K, Bergstrom A, Kindahl H, Lagerstedt AS. Increased plasma concentrations of vasopressin, oxytocin, cortisol and the prostaglandin F2alpha metabolite during labour in the dog. Acta Physiol Scand 2003; 179: 281-287, doi: 10.1046/ j.0001-6772.2003.01178.x

11. Garcia-Villar R, Toutain PL, Ruckebusch Y. Pattern of electrical activity of the ovine uterus and cervix from mating to parturition. J Reprod Fertil 1984; 72: 143-152, doi: 10.1530/ jrf.0.0720143.

12. Lye SJ, Freitag CL. An in-vivo model to examine the electromyographic activity of isolated myometrial tissue from pregnant sheep. J Reprod Fertil 1988; 82: 51-61, doi: 10.1530/ jrf.0.0820051.
13. Evans HE, Sack WO. Prenatal development of domestic and laboratory mammals: growth curves, external features and selected references. Zentralb/ Veterinarmed C 1973; 2: 1145.

14. Pfaffl MW, Horgan GW, Dempfle L. Relative expression software tool (REST) for group-wise comparison and statistical analysis of relative expression results in real-time PCR. Nucleic Acids Res 2002; 30: e36, doi: 10.1093/nar/30.9.e36.

15. Leavitt WW, Okulicz WC, McCracken JA, Schramm W, Robidoux WF Jr. Rapid recovery of nuclear estrogen receptor and oxytocin receptor in the ovine uterus following progesterone withdrawal. J Steroid Biochem 1985; 22: 687-691, doi: 10.1016/0022-4731(85)90272-9.

16. Luz MR, Bertan CM, Binelli M, Lopes MD. Plasma concentrations of 13,14-dihydro-15-keto prostaglandin F2-alpha (PGFM), progesterone and estradiol in pregnant and nonpregnant diestrus cross-bred bitches. Theriogenology 2006; 66: 1436-1441, doi: 10.1016/j.theriogenology.2006.01.036.

17. Gram A, Boos A, Kowalewski MP. Uterine and placental expression of canine oxytocin receptor during pregnancy and normal and induced parturition. Reprod Domest Anim 2014; 49 (Suppl 2): 41-49, doi: 10.1111/rda.12295.

18. Kuiper GG, Carlsson B, Grandien K, Enmark E, Haggblad J, Nilsson $\mathrm{S}$, et al. Comparison of the ligand binding specificity and transcript tissue distribution of estrogen receptors alpha and beta. Endocrinology 1997; 138: 863-870.

19. Larcher A, Neculcea J, Breton C, Arslan A, Rozen F, Russo $C$, et al. Oxytocin receptor gene expression in the rat uterus during pregnancy and the estrous cycle and in response to gonadal steroid treatment. Endocrinology 1995; 136: 53505356.

20. Challis JR. Sharp increase in free circulating oestrogens immediately before parturition in sheep. Nature 1971; 229: 208, doi: 10.1038/229208a0.

21. Vegeto E, Shahbaz MM, Wen DX, Goldman ME, O'Malley BW, McDonnell DP. Human progesterone receptor A form is a cell- and promoter-specific repressor of human progesterone receptor B function. Mol Endocrinol 1993; 7: 12441255.

22. Mesiano S, Chan EC, Fitter JT, Kwek K, Yeo G, Smith R. Progesterone withdrawal and estrogen activation in human parturition are coordinated by progesterone receptor $A$ expression in the myometrium. J Clin Endocrinol Metab 2002; 87: 2924-2930, doi: 10.1210/jcem.87.6.8609.

23. Taverne MA, Naaktgeboren C, Elsaesser F, Forsling ML, van der Weyden GC, Ellendorff $F$, et al. Myometrial electrical activity and plasma concentrations of progesterone, estrogens and oxytocin during late pregnancy and parturition in the miniature pig. Biol Reprod 1979; 21: 1125-1134, doi: 10.1095/ biolreprod21.5.1125.

24. Klarenbeek M, Okkens AC, Kooistra HS, Mol JA, Bevers MM, Taverne MA. Plasma oxytocin concentrations during late pregnancy and parturition in the dog. Theriogenology 2007; 68: 1169-1176, doi: 10.1016/j.theriogenology.2007.08.017. 